\title{
A Case of Writing-oriented Literary Therapy for Easing Anger Emotion - Focusing on Male Inmates of a Correctional Facility
}

\author{
Yonsuk Chae ${ }^{1}$, Heakyung $\mathrm{Kim}^{2}$, Deugja Moon ${ }^{3}$ \\ ${ }^{I}$ Professor, 41566 Dept. German Teachers College, Kyungpook National Univ., Daehakro 80, Buk-gu, \\ Daegu,Korea, chaeys@knu.ac.kr \\ ${ }^{2}$ Lecture Professor, 41566 Dept Literarytherapy of Kyungpook National Univ., Daegu, Korea, \\ dosa1983@hanmail.net \\ ${ }^{3}$ Lecture Professor, 48513 Pukyong National Univ., Busan, Korea, md286@hanmail.net \\ Corresponding author: Yonsuk Chae
}

\begin{abstract}
The purpose of this study is to examine the effects of the literary therapy program, by utilizing writing, in reducing anger for male inmates in Korean correctional facilities. The program was carried out from March to December with the Cultural Cooperation Project of the Ministry of Justice in 2015. The subjects were twelve male inmates. In the literary therapyprogram the reduction of the anger emotion was analyzed. First, in terms of anger-out, it was confirmed that the level of anger-out was lower than before the program execution. Second, in terms of anger-in, it was confirmed that the level of anger-in was lower than before the program execution. Third, in terms of anger control, it was confirmed that the level of anger control was higher than before the program execution. Consequently, it can be said that the literary therapy program has a positive effect on anger emotion for male inmates because it reduces the levels of anger-out/in and improves the level of the anger control. In addition, in terms of the aspects of anger emotion, using the theme-based research analysis, it seems that the healing effect of writing has opened up a new horizon by integrating the wounded past with the recoverable present through the medium of literature.
\end{abstract}

Keywords: Literary Therapy, Male Inmates, Anger Emotion, Healing Effect of Writing, Reduction of Anger Expression

\section{Introduction}

The correctional \& rehabilitative education that is being carried out now in South Korea is being formed in the mainstream primarily by themes, which indirectly purify emotion, mostly such as vocational training, life guidance and art. Of course, even in addition to these thematic areas, the rehabilitative activity, or counseling, related to religion is giving a help in many ways to inmates. However, this can be considered to be in an excessively insufficient situation for programs that deeply recognize and reflect on inmates' problems of mind, namely, the inner side like anger or emotional anxiety, and guilty conscience. Above all, researchers aimed to offer a 'safe space(Geschützter Raum)' through the writing-oriented literary-therapy program, allowing these male inmates, whose body and mind are 'confined' in a certain space, to freely express their feelings.

The term correctional facilities used in this paper refers to prisons, detention centers, etc. based on

Received:August 15, 2020; $1^{\text {st }}$ Review Result: September 29, 2020; $2^{\text {nd }}$ Review Result:November 16, 2020 Accepted: December 28, 2020 
the Penal Execution act, and the correction of consultation is limited to the scope. In addition, correctional facilities refer to treatment spaces in which correctional administration is implemented, including treatment of prisoners according to the Penal Enforcement act, including the material element of the facility. In this study, this concept is used in such a scope.

Accordingly, the research contents of this study contained only the details ranging from the 1st session to the 15th session through tracing and interpreting only the contents of representing these processes on a paper. A case was presented from a text of Participant 1, 'idiot' as a nickname that typically shows this process. Also, this study received prior consultation on the program from eight experts and specialized literary therapists in order to verify the effect of the writing-oriented literary-therapy program in reducing and easing anger emotion. Other than that, the descriptive method of this research outcome used the researcher-centered technique.

In addition, examining previous research on whether the literary therapy program is effective for the anger control, Lee Mi-jin(2010) explains the literary therapy as one of a very efficient method regarding the counseling technique that addresses a problem related to the anger control[1]. The reason is that the cognitive understanding about emotion can induce the reconstruction of a psychological wound through literary therapy. In Pennebaker(1988)'s research, the impact through writing was analyzed by having the research subject as a psychological trauma patient. In this study, writing is being especially explained as a very adequate approach in leading to cognitive restructuring[2].

In this sense, the anger emotion, which was seen through the writing-oriented literary therapy program, is not the necessary and sufficient condition for the crime of aggression and assault. But the inmates were premised to be able to averagely disclose higher levels of anger. Generally among inmates, the violent inmates show higher anger than non-violent inmates. Also, anger is the strongest predictive factor of aggression in adolescents who are held in the facility, and is associated with a physical attack on a facility staff(Howell, L., Day, A., Williamson, P., Bubner, S., Parker, A., Heseltine, K., 2005)[3].

First and foremost, it is necessary to examine the theory of whether there is a linkage with crime, and the extent this depends on how an inmate recognizes anger. This is as follows. Firstly, the priority needs to be given first to the awareness on their own negative emotion to control the angry feeling or expression. Still, what perceives own emotion can be considered to be the starting point available for regulating anger expression. The role of perceiving emotion in anger is being shown by Goleman(1978)'s research result as coming to unlikely act in a rage if an individual is experiencing anger realizes that "what I am experiencing and feeling is anger" in a state of anger[4]. In Shin Jeongmi(2013)'s research, the clarity of the emotion recognition displayed a significant positive correlation with the anger control, which is a functional way of expressing anger. And the functional way of expressing anger was predicted significantly[5].

In addition, American fury specialist Mckay(2003) looked upon "what is necessary for anger as two things," namely like gasoline and matches in terms of a concept dubbed 'a trigger thought.' $\mathrm{He}$ is regarding gasoline just as stress. Furthermore, he is emphasizing that so many complex factors exist that cause stress, but that a match is needed for arousing anger with seeing that it just doesn't lead to anger. Furthermore, with the anger-inducing thought, and the idea like a match of igniting fuel called stress, these are just considered to be the trigger thoughts[6]. The trigger thought, which arouses anger, is shown with diverse methods and forms in many aspects of daily life. That is to say, the feelings of disappointment, resentment and decision become the starting point of all the trigger thoughts.

Even if the male inmates of the correctional facility became a prisoner by their own wrongdoing, they are hurt more due to dissatisfaction and resentment as if feeling being abandoned themselves by a difference in attitudes of family members or people around. As for a situation of being committed to the facility now that cannot be tolerated even by oneself, the recognition dubbed 'what oneself is also a victim' may exist. And a state can be continued that is suppressing anger, not a wrath getting angry and screaming. 


\section{Research Method}

\subsection{Research Participants' General Characteristics and Their Role Asinmates}

The inmates involved in this study refer to those sentenced to prison, imprisonment or detention and those ordered to host a labor site for failing to pay full fines or fines. An unconvicted prisoner means a person arrested or executed by an arrest warrant as a criminal suspect or a criminal defendant. Inmate means a prisoner, a prisoner pending, a confirmed death penalty, or any other person held in a prison, detention center, or branch in accordance with law and due process.

The legal status of inmates has changed considerably according to certain countries or times. The view of international law concerning the status of prisoners, the view of the rule of law, calls for the inmates to be recognized as subjects of freedom and rights, not just objects, but as subjects of freedom and rights like ordinary citizens. In light of the principle of the social state of our Constitution, it is said that in modern society there is a duty to guarantee the basic rights of the state to defend and develop the basic rights of the inmates who are deprived of their freedom.

First of all, this study is based on a research method of observing and identifying what meaning the inmates themselves are given to the texts that prisoners wrote during 15 sessions starting from the first session. A case was presented from the text of participant 1 , nickname 'idiot' that typically shows this process. To verify the effect of the writing-oriented literary therapy program for reducing and easing anger emotion, this study received prior advice on the program from eight experts and specialized literary therapists. Even in addition to this, the descriptive method of this research result used the researcher-centered technique. This study will explore how the writing-oriented literary therapy program, which was conducted targeting 12 male inmates at B correctional facility in Busan from March 1, 2015 to December 30, can change anger emotion immanent in their inner side.

[Table 1] Research Participants' General Characteristics

\begin{tabular}{|c|c|c|}
\hline Variable & Classification & $\mathrm{N}(\%)$ \\
\hline Gender & Male & $12(100.0)$ \\
\hline \multirow{4}{*}{ Marital status } & Married & $2(16.7)$ \\
\hline & Unmarried & $3(25.0)$ \\
\hline & Separation and divorce & $3(25.0)$ \\
\hline & Cohabitation & $4(33.3)$ \\
\hline \multirow{5}{*}{ Education level } & Elementary school graduation & $1(8.4)$ \\
\hline & Middle school graduation & $2(16.7)$ \\
\hline & High school dropout & $2(16.7)$ \\
\hline & High school graduation & $7(58.2)$ \\
\hline & University graduation & $0(00.0)$ \\
\hline \multirow[t]{2}{*}{ Age } & $\begin{array}{c}21 \text { years old } \sim \text { Under } 30 \text { years } \\
\text { old }\end{array}$ & $1(8.4)$ \\
\hline & 31 years old $\sim$ Below 40 years & $4(33.3)$ \\
\hline
\end{tabular}




\begin{tabular}{|c|c|c|}
\hline \multirow{4}{*}{ old } & $4(33.3)$ \\
\cline { 2 - 3 } & $\begin{array}{c}41 \text { years old } \sim \text { Under 50 years } \\
\text { old }\end{array}$ & $3(25.0)$ \\
\cline { 2 - 3 } & Over 51 years old & $2(16.7)$ \\
\hline \multirow{5}{*}{ Prison term } & Less than 5 years & $3((25.0)$ \\
\cline { 2 - 3 } & 6 years $\sim$ Under 10 years & $0(00.0)$ \\
\cline { 2 - 3 } & 11 years $\sim$ Below 15 years & $4(33.3)$ \\
\cline { 2 - 3 } & More than 16 years & $3(25.0)$ \\
\cline { 2 - 3 } & Indefinite sentence & \\
\hline
\end{tabular}

This study was aimed to explore how the writing-oriented literary-therapy program, which was performed targeting 12 male inmates of B correctional facility in Busan from March 1, 2015 to December 30, can change the feelings of anger inherent in their inner selves. Accordingly, the general characteristics of twelve people who had participated in the study were suggested in $<$ Table $1>$. The research participants' age and participating personnel comprised of 12 people with 1participant $(8.4 \%)$ at the ages of 21 30 years, 4 participants $(33.3 \%)$ at the ages of 31 40 years, 4 participants $(33.3 \%)$ at the ages of $41 \sim 50$ years, and 3 participants $(25 \%)$ at the ages over 51 years. The education level appeared to be elementary school graduation with 1 participant $(8.4 \%)$, middle school graduation with 2 participants (16.7\%), high school expulsion with 2 participants(16.7\%), high school graduation with 7 participants (58.2\%), and none participants with university graduation. The marital status is indicated to be the married with 2 participants $(16.7 \%)$, the unmarried with 3participants $(25 \%)$, separation \& divorce with 3participants(25\%), and cohabitation with 4participants(33.3\%). The remaining prison term is shown to be under 5 years with 2participants(16.6\%), 6 years $\sim$ below 10 years with 3 participants $(25 \%)$, 11 years under 15 years with none, over 16 years with 4 participants(33.3\%), and life sentence with 3 participants $(25 \%)$.

\subsubsection{The Relaxation of Anger Feeling and the Effect of the Writing-oriented Literary Therapy}

When these researchers carried out the writing-oriented literary therapy program, targeting male inmates of the correctional facility, most participants said they join 'because of liking literature' or 'due to curiosity.' However, there was also a participant in fact who was completely far away from literature among those participants. Nevertheless, even so the participants could have a new insight by meeting their unconscious self through solving their own story based on writing in various forms amidst the 'safe fence'called literary therapy.

\subsubsection{The Process by Composition and by Phase in the Writing-oriented Literary Therapy Program}

To achieve the objective of the writing-oriented literary therapy program, for easing anger emotion in male inmates of the correctional facility, this study formed the 4-phase program of Initial Phase, Action Phase, Integration Phase, and Reorientation Phase. This is in accordance with the tetra system that is the process of group literary therapy. This program consisted of a total of 15 sessions with 100 minutes per session. In addition, this program was begun with a'feeling of reading a book' every session. After carrying out the activity according to the theme of the session, it was finished with the activity of allowing the present feeling and emotion to be expressed with 'a word, a sentence.' 


\subsection{Research Results}

\subsubsection{The Mitigation of the Feeling of Anger and the Effect of the Writing-oriented Literary Therapy}

Pennebaker(2007) carried out an experiment of the writing on psychological trauma. As a result of the experiment, he reported that more than $70 \%$ of the participants clearly understand about a traumatic event themselves through writing[7]. Especially noteworthy among the rest corresponds to the expressions that were used in these people's answers to the open-ended question about general value of writing, with around half included the words like 'realize, 'understand,' 'solve,' 'resolving.' Many on the subject of writing, a participant becomes conscious of what I couldn't say usually. In other words, it is meant to proceed with finding own emotion beyond 'routinized language' through reading or writing(Byun Hak-su, 2005)[8]. Carroil(2005) mentioned that "writing plays a role of making it have a proper word for thinking and feeling, which had never been able to be taken out of the mind. An individual can be helped with healing by being allowed to utter a voice despite our actual experience on what is tabooed socially, namely, on a matter like death"[9].

A point that the writing on own experience effected self-healing along with pursuing self-identity is being continuously reported previously in research at home and abroad. Lutz Von Werder(2004) mentioned that the memory and repetition of oneself through writing become a creative act and that this itself already has an impact on healing while describing own life as a story with thinking that writing is a self-healing method. In essence, he said that objectifying himself to writing itself leads to being created the composure of 'distancing,' which makes oneself take a step back to look at, and that this relaxation becomes a motive of healing[10]. Also, Jeong Seong-ok(2016) mentions that the literary therapeutic writing makes it available not only for telling their own story safely through literary media, but also for having an insight into one's unconscious self through writing a poem, with the use of symbolism and metaphor, or through creating a fictional story, and through writing a fairy tale unlike the writing in the different form[11].

\subsubsection{Composition and the Step-by-step Process of the Writing-oriented Literary-therapy Program}

In this study, in order to achieve the purpose of the writing-oriented literary therapy program for the relaxation of anger feelings of male inmates in correctional facilities, four-step programs of Introductory Phase, Action Phase, Integration Phase, and Reorientation Phase were organized in accordance with the Tetra System, a process of group literature therapy. The program consists of a total of 15 sessions with 100 minutes per session. The program also began with "feeling like reading a book" in each session, followed by activities based on the topic of the session and ended with activities that led to the expression of current feelings and feelings in a single sentence.

First of all, to explain the entire steps of the four-step program, the purpose of the "Initial Phase" was to form a trust between participants and therapists to resolve the awkward and tense atmosphere, and to this end, I freely wrote as a recollection of the "time that I shone the most." Writing is often a burden to write well, but if you trust a therapist and follow him, it creates a playful atmosphere that naturally becomes writing.

In addition, activities provided an incentive to participate in the program with a sense of belonging and responsibility to the group by making them understand the goals and contents of the entire program, explaining the rules to be followed during the program's execution, and writing a pledge. Participants were in the same correctional facility but lived in isolation from each other, so they often met for the first time in a group of literary therapy programs, so the introduction phase lasted up to the second session. First of all, to explain the entire steps based on the above process, the purpose of the "Initial Phase" was to form a trust between participants and therapists and to resolve the awkward and tense atmosphere, and to this end, I freely wrote as a recollection of the "time that I shone the most." Writing 
is often a burden to write well, but if you trust a therapist and follow him, it creates a playful atmosphere that naturally becomes writing. It provided an incentive to participate in the program with a sense of belonging and responsibility to the group by making them understand the goals and contents of the entire program, explaining the rules to be followed during the program's execution, and writing a pledge. Participants were in the same correctional facility but lived in isolation from each other, so they often met for the first time in a group of literary therapy programs, so the introduction phase lasted up to the second session.

In the next stage, Action Phase, participants were immersed in writing their own text, and they had the opportunity to express their feelings and experience catharsis through writing. By writing and talking about the problems of one's life, such as 'discovering happy memories', 'living with a new type of family', 'family is my strength', and 'sympathy through literary expression', 'searching for the language of my soul' and 'meaning of human dignity and existence', they returned each other's feelings and feelings to positive emotions, and provided an opportunity to communicate through the technology of sharing each other. At this time, various writings, which were used as various literary therapy tools, are encouraged to express the latent emotion of unconsciousness within the participants. Your own text and poetry are expressed in your own language, and it reveals unconsciousness, explores relationships, shows the lucidity of reason, indirectly affects behavior, and promotes growth (Malchiodi, 2005)[12]. At this time, participants experience the dynamics of unconsciousness through sharing activities and the text and poetry of others who are different from me, and experience the discovery and change of their current emotions in the program. Especially at this stage, anxietyand negative feelings of the male inmates in correctional facilities were expressed to other participants in a safe and respected therapeutic atmosphere. In addition, it provided an opportunity for expression by creating an atmosphere in which he could carefully express his feelings and confidence in his family, friends and colleagues. This was done in a total of six sessions, from three to eight.

The third stage, Integration Phase, is a stage in which the therapist understands and integrates the psychological dynamics of the execution stage as his or her own through the activities carried out in the execution stage. The main activities included "becoming an independent subject through humanistic insights," "living as a father in this era," "meeting with a true self," "living as a man of this era," and "the joy of writing poems." And he experienced the process of uncoordinated integration with his unconscious mind. In particular, personal integration is gained in the process of exchanging positive feelings with other participants or therapists. The integration phase encourages participants to have a perception and emotional understanding of themselves through various activities and writing. Here, it induces participants to speak of positive self-experience, to bring out another positive idea, and to speak of their own psychological deficiencies.

In this way, if psychological deficiency is expressed honestly, it will affect other participants, which will actively reverse the group. At this stage, the positive emotions of each other's writing were returned and shared with each other, then compressed into one word or sentence to express their feelings and feelings. In essence, through the activities expressed in one sentence, one finds a language that represents a participant's situation. Through this training, one recognized the difference between one's actions and emotions and simply expressed the emotion, thus bringing out memories that had not been expressed in the past or were forbidden from expression within literary therapy. It can be said that putting down resistance or rejection in the participants' verbal expression of their feelings is the starting point of treatment. The integration phase took place in a total of five sessions, from the 9th to the 13th. Finally, in the Reorientation Phase through the "Wisdom of Learning from Grass Flowers" and "50 Self-Proud Things," participants who overcame their anger expressed their desired future and reflected on their commitment to the future. Through this, we planned to experience tension-relieving and positive emotions and share the future self-image that each wants.

Then they took time to look back on to previous sessions and organize themselves and their groups 
by reading their own stories in the archives. At this stage, participants were able to recognize their tasks and set new directions by writing about new dreams and future awards or expressing them in language. This step was carried out in a total of two sessions, from 14 to 15. As above, this researcher had a goal to reach in the program's session, but if the situation changed while following the participants' narratives, it proceededwith respect to the participants' expressions.

To summarise,the four-step systemis as follows:First of all, explaining the whole phases based on 1) Initial Phase; as the relationship formation stage, the aim was to ease the awkward and tense atmosphere by forming the confidence between participants and a therapist, and the intimacy among participants. For this, the writing was freely made with the reminiscence of 'The times I shined the most.' Successively in 2) Action Phase; as the stage in which a participant is absorbed in writing own text, the participant had an opportunity of expressing own emotion and experiencing catharsis through writing. An opportunity was offered that feels empathy through the skills of giving back mutual sentiment and feeling as positive emotion and of sharing each other through writing and talking in turn a problem of own life, such as 'discovering happy memory,' 'living with a family in the new form,' 'family as my power,' 'feeling empathy using literary expression,' 'finding language in my soul,' and 'a meaning of human dignity and existence.' This was carried out over totally 6 times from the 3rd session to the 8th session. In 3) Integration Phase; as the third stage, it is the phase that allows a participant to understand and integrate psychological dynamics in the Action Phase into own thing through the activity that the therapist implemented in the Action Phase, which is the previous stage. The major activity contents included 'becoming the independent subject through humanistic insight,' 'proceeding with living as a father in this era, 'meeting with the true self,' "living as a man in this period' and 'enjoying writing a poem,' and were discovered the image that had been hidden in oneself with writing even a darning poem. The Integration Phase was formed across a total of5 sessions from the 9th session to the 13th session. Finally, 4) Reorientation Phase allowed the participants, who got over anger, to express own desired future and to reflect on a pledge for the future through 'wisdom learned from the grass flower' and through '50 things of self-praise.' In this phase, a participant could establish new direction recognizing their own task by the writing of a new dream and future image or by the verbal expression. This phase was formed across a total of two sessions from the 14th session to the 15th session.

\subsubsection{Verification on the Ccomposition and Ccontent Validity of the Writing-oriented Literary-therapy Program}

To evaluate the composition and content validity of the writing-oriented literary-therapy program,that was presented in this study, the researchers subdivided the whole program contents into activity details of each session. , Afterwards, requested a rating from an expert related to counseling and treatment as to analyse whether the program contents and activities were formed suitably for the objective for each session. The experts, who took part in assessment, were composed of a total of eight people who hold a consultation and treatment certificate. These people's age distribution was between 42 62 years old. The average age was 53 years old. The average counseling career was 8 years. A rating was allowed to be given with 5-point scale as for contents in each activity. It implies 5 points as 'very adequate,' 1 point as 'almost not adequate.' The rating result was calculated by CVI(Content Validity Index) that Haxbleton and his colleagues did put to practical use(Guilford \& Fruchter, 1973)[13]. The writing-oriented literarytherapy program was adequately evaluated on each unit activity of a total of 58 pieces, were formed in line with the objective by each session. With 4 points and 5 points as to 'adequate' and 'very adequate', the sum of the graded scores stand at 1,238 points. The total score of rating with $1 \sim 5$ points comes to 1,412 points. Thus, the content validity indicated $\mathrm{CVI}=1,238 / 1,412=.88$. This score shows that the content composition of the writing-oriented literary-therapy program was formed suitably for the objective of the program. 


\subsubsection{Media Selection by Session in the Writing-oriented Literary-therapy Program}

It is not that a book needs to be certainly used in the media selection of the writing-oriented literarytherapy program however, in light of a characteristic in the Ministry of Justice's Cultural and Arts Education Support Project, the book purchase cost was subsidized.Thereby having become an opportunity that male inmates can encounter high-level literature. A book necessary for the program by the session was supplied two weeks before in order for the participant to be capable of reading a sufficient amount. According to previous researchs(Byeon Hak-su, 2002; Lee Suk-jin, 2003; Gwak Yeong-nam, 2005, Lee Seong-ok, 2006) empathy is done by the homogenization principle and that a new insight is made by the heterogeneity principle regarding the media selection of the writing-oriented literary-therapy program, the books and media were chosen by considering the objective by each session, participants' age group, preference, point of time, and a writing theme. Among others, the functions that will need to be possessed by a text of being suggested in literary therapy, namely, what a participant can tell with having a protective film on oneself during talking about a text, and what gives a community spirit that defends oneself within a group were considered[8].

In addition, there is a case of choosing a medium according to a situation given the media selection in the composition of a program for reducing anger emotion in the previous research. This media selection by situation may rather interrupt a participant's empathy. For example, if male inmates with high anger are offered a book with the topic of fury, it may rather lead to coming to defend own problem and to being disturbed empathy. Hence, a book was chosen by emphasizing the present sentiment and emotion that the male inmates in the correctional facility are experiencing rather than the media selection depending on a situation. This outcome implies a fact that the writing-oriented literary therapy program has a significant influence upon the changing of the feeling of anger and is an important factor in the generation of positive emotion. Through the medium called literature the impact of this study opened a new horizon for participants to integrate the wounded past to the recoverable present.

\subsubsection{Case Introduction: Expression of Anger Emotion shown in the Writing by Participant 1, Nickname, 'Idiot'}

As can be known in the text written by the following Participant 1, 'idiot' as a nickname, the aspect of expressing anger, was indicated in his writing during the execution of the literary therapy program. This can be read to be gradually changed into relaxation and reduction in anger emotion from the feeling of anger as the session continued. Also, even if the male inmates of the correctional facility became in the position of an inmate due to wrongdoing, they are expressing more hurt caused by sorrow and resentment, as if having been abandoned themselves. That is to say, what the participants recognize that 'I am also a victim' as for the current imprisonment situation that they cannot condone even themselves can be considered to have been a state of suppressing anger, not of expressing fury losing temper and screaming.

However, given introducing the case of 'idiot' as a nickname when having been given a set word dubbed 'what had been hidden in me ' ' in the work phase for the 7th session of the program, the participant whose nickname is 'idiot'"showed the violence, which had been hidden in me, the gasping fear beneath it, and the expressions related to myself. He expressed that he uses more violence because of disliking it oneself, uses greater violence with trampling on fear and pretending not to know, that's how life runs away all its life, fear..., and the fire that had been hidden in me!". People who get angry easily have a great amount of propensity or a sensitive to self-defense and self-protection. When seeing them in another aspect, they can be considered to be an inwardly weak person. To control angry expression, the recognition of own negative emotion needs to be prioritized. What perceives own sentiment can be said to be the starting point available for regulating angry expression. Goleman(1978)'s research result, as saying of coming to be unlikely carried away by anger if an individual can realize 
that "what I experience and feel now is fury" in a state of wrath, is showing that a role of emotional awakening is significant in anger[4]. In the 11th session of the program, the writing with the parody of 'To live is to be' by O Se-yeong led to what 'idiot' mentioned that 'To live is to complete love.' As a meaning on the time that had been together with 'the person' in memory with laying down own thought and stubbornness, the positive value is being aimed for what proceeds with finding the power oneself available for enduring the present time is just to live.

\section{Conclusion and Suggestions}

To conclude, the outcome of this study, can be summarized with three findings. Firstly, this study specifically analyzed the effect of literary therapy program on inmates of a correctional facility focusing on a cases, providing initial research on the field that previous studies failed to address previously. Second, as for the effect of simply applying the literary therapy program on the proposal of real inmates' present feeling or situation, with the qualitative analysis result, led to being able to confirm which part is desperately needed for prisoners in the literary therapy program. Third, it can be stated through various literacy meanings that there can be a significant reduction in the deep-seated feelings of anger from the individuals background and emotion for the correctional facility inmates.

On the other hand, this study has the following limitations despite this implication. First, a problem exists about which the generalization of this research results in somewhat unreasonable conclusions because the research subjects were set to be the ones of a specific correctional facility. Second, the literary significance was examined focusing on angry feelings of correctional facility inmates but future research needs to further expand in the analytical scope into the theme available for identifying inmates' diverse feelings or emotional characteristics.

Third, intense research needs to address the development of a program to integrate various therapy programs such as music, fine arts and play-acting as well as literary therapy centering on story and writing into the correctional facility.

The final three conclusions drawn from this study can be summarized by the following. First, negative emotions of male inmates were shown to have a significant relationship with expressions of anger. Second, as a result of the application of the writing-oriented literary therapy program, the expression of anger among male inmates in correctional facilities was reduced. Third, the literature therapy program applied at the correctional facility was able to bring about emotional changes and positive emotions of male inmates and observe various emotional changes sessions progressed.

Furthermore, the results of this study suggested the possibility of using a writing-oriented literary therapy program for emotional and psychological aspects within the correctional facility. The study is relevant in that it attempted to link a humanities sensibility with a writing literature therapy program in the correctional program within the limits of existing awareness education and rehabilitation education.

\section{References}

[1] Mijin Lee, The effect of cognitive behavioral literature therapy programs on anger control in college students, Kyungpook National University Graduate School, Master's Thesis, (2010)

[2] J. W. Pennebaker, Confiding traumatic experiences and health. In S. Fisher \& J. Reason (Eds.), Handbook of life stress, cognition and health, (1988), pp.669-682.

[3] K. Howells, A. Day, P. Williamson, S. Bubner, S. Jauncey, A. Parker, K. Heseltine, Brief anger management programs with offenders : Outcomes and predictors of change, The Journal of Forensic Psychiatry \& Psychology, (2005), Vol.16, No.2, pp.296-311. 
[4] D. Goleman, Journal of Altered States of Consciousness, Baywood Publishing Company, (1976)

[5] Jungmi Shin, The Effect of Emotional Perception Clarification on the Way of Expression of Anger: The Mediation Effect of Anger Reflection, Graduate School of Catholic University, Master's Thesis, (2013)

[6] M. McKay, P. D. Rogers, J. McKay, When anger burts: Quieting the storm within, New Harbinger Publications, (2003)

[7] J. W. Pennebaker, Writing to Heal: A Guided Journal for Recovering from Trauma and Emotional Upheaval, Translated by Bonghee Lee, Academic Governor, (2007)

[8] Haksu Byun, The intergrated Literary Therapy, Hakgisa, (2006)

[9] R. Carroii, Finding the words to say It: The healing power of poetry, Evidence-Based Complementary and Alternative Medicine, (2005), Vol.2, No.2, pp.161-172.

[10] Lutz Von Werder, Kreatives Schreiben, Schibri-Verlag, (2004)

[11] Seungok Jung, A narratives study of literary therapeutic writing and relational self-identity - based on Paul Ricour's theory of narrative identity, Kyungpook National University, Doctoral Dissertation, (2016)

[12] C. A. Malchiodi, Expressive Therapies, Guilford Publications, (2005)

[13] J. P. Guilford, B. Fruchter, Fundamental statistics in psychology and education (5th ed), McGraw-Hill, (1973) 